\title{
IMPLEMENTASI PENDIDIKAN INKLUSIF DI KOTA TASIKMALAYA (STUDI KASUS: SDN GUNUNG LIPUNG 4 KOTA TASIKMALAYA)
}

\author{
Puji Imam Muttaqien1 \\ ${ }^{1}$ Program Studi Magister Administrasi Negara, STIA YPPT Priatim Tasikmalaya \\ e-mail: pujiimammuttaqien@gmail.com
}

\begin{abstract}
This research aims to determine how the success or failure of implementation of the education policy inclusive in Tasikmalaya city based on the regulation of Tasikmalaya Mayor Number 46 year 2014 about the implementation of inclusive education in Tasikmalaya City. The problems that arise include facilities and infrastructures that still lack support of the inclusive education process, funding sources for the course of inclusive education programs and human Resources Special escort teachers (GPK) that are still lacking and need additions. In research is an analytical descriptive study by using data collection techniques such as observation of the research object in a manner of frankly and later subsequent interview techniques on informant relevant to this study and documentation studies. For the data analysis techniques in this research is conducted through three activities that occur simultaneously namely data reduction, data presentation, and withdrawal of conclusions or verification. As for the analysis of data on this research use triangulation techniques. Based on the results of research in SD Negeri 4 Mount Lipung consistently and sustainably enough to run an inclusive education program. But there are still some issues that arise such as communication that lacks details between the education office as a policy maker and the school as an impelentor or policy executor. Still need special attention from the Government related to human resources special Companion teachers (GPK), facilities and infrastructure resources that support inclusive education programs and also special funding sources for inclusive education programs. But SD Negeri 4 mount Lipung can be categorized successfully in the implementation of the inclusive education program policy.
\end{abstract}

Keywords: policy implementation, inclusive education

Received: 04 Mei 2020

Accepted: 30 Mei 2020

Published: 18 Juni 2020

\section{PENDAHULUAN}

Pendidikan adalah modal yang sangat penting dan perlu di miliki oleh semua manusia khususnya anak-anak dalam menjalani kehidupan berkelompok atau bermasyarakat. Pendidikan pula faktor yang sangat penting bagi masyarakat, maju mundurnya kualitas masyarakat atau bangsa sangat bergantung pada pendidikan yang ada pada rakyat atau masyarakat tersebut.

Ki Hajar Dewantara sebagai Bapak Pendidikan Nasional Indonesia mengatakan pendidikan tersebut adalah merupakan tuntutan didalam hidup tumbuhnya anakanak, adapun maksud dari pendidikan yaitu menuntun segala kodrat yang ada 
pada anak-anak tersebut agar mereka dapat mencapai keselamatan dan kebahagiaan (Khoeriyah, 2019).

Pendidikan adalah hak semua warga negara bangsa seperti yang tertuang dalam Undang-Undang (UU) Sistem Pendidikan Nasional No. 20 Tahun 2003, pendidikan adalah usaha sadar dan terencana untuk mewujudkan suasana belajar dan proses pembelajaran agar peserta didik secara aktif mengembangkan potensi dirinya untuk memiliki kekuatan spiritual keagamaan, pengendalian diri, kepribadian, kecerdasan, akhlak mulia, serta keterampilan. Dengan adanya UU tersebut diharapkan terbentuknya pendidikan yang adil tanpa membedakan kondisi siswa normal dengan siswa berkebutuhan khusus.

Jumlah penyandang disabilitas pada tahun 2020 di Kota Tasikmalaya menurut data dari Dinas Sosial Kota Tasikmalaya sekitar ada 2000 orang yang tercatat penyandang disabilitas di Kota Tasikmalaya, mereke tersebar di berbagai 10 Kecamatan di Kota Tasikmalaya. Meski demikian data yang lebih tepat belum bisa dipastikan, karena tidak jarang keluarga penyandang disabilitas sering menyembunyikan identitas anggota keluarganya yang difabel untuk menghindari rasa malu dan masih mengganggap aib bagi citra keluarganya. Berikut data lengkap penyandang disabilitas di Kota Tasikmalaya.

Tabel 1.

Data Penyandang Disabilitas di Kota Tasikmalaya Tahun 2020

\begin{tabular}{llc}
\hline No & Kecamatan & Total Disabilitas \\
\hline 1 & BUNGURSARI & 213 \\
2 & CIBEUREUM & 228 \\
3 & CIHIDEUNG & 207 \\
4 & CIPEDES & 198 \\
5 & INDIHIANG & 167 \\
6 & KAWALU & 403 \\
7 & MANGKUBUMI & 420 \\
8 & PURBARATU & 149 \\
9 & TAMANSARI & 292 \\
10 & TAWANG & 105 \\
\hline JUMLAH & & $\mathbf{2 3 8 2}$ \\
\hline
\end{tabular}

Sumber: Dinas Sosial Kota Tasikmalaya

Menurut Hildegun Olsen dalam Tarmansyah (2007) pendidikan Inklusi adalah sekolah harus mengakomodasi semua anak tanpa memandang kondisi fisik, intelektual, sosial emosial, linguistik atau kondisi lainnya. Dan juga sebuah pelayanan pendidikan bagi peserta didik yang mempunyai kebutuhan pendidikan khusus di sekolah reguler (SD, SMP, SMA dan SMK) yang tergolong luar biasa baik dalam arti kelainan, lamban belajar maupun berkesulitan belajar lainnya (Mustarjudin, 2017).

Berdasarkan Peraturan Walikota Tasikmalaya Nomor 46 Tahun 2014 Tentang Penyelenggaraan Pendidikan Inklusif di Kota Tasikmalaya yang di maksudkan peserta didik berkebutuhan khusus antara lain:

1) Peserta didik berkebutuhan khusus terdiri dari: peserta didik yang memiliki kelainan/hambatan fisik, emosional, intelektual, mental dan/atau sosial; dan/atau peserta didik yang memiliki potensi kecerdasan dan/atau bakat istimewa. 
2) Peserta didik yang memiliki kelainan sebagaimana dimaksud pada ayat (1) terdiri atas: tunanetra atau kelainan penglihatan, tunarungu atau kelainan pendengaran, tunawicara atau kelainan bicara, tunagrahita atau kelainan kecerdasan/intelektual,tunadaksa atau kelainan fisik dan/atau fungsi gerak,tunalaras atau kelainan emosi dan/atau perilaku, berkesulitan belajar, lamban belajar, autistik, gangguan motorik, korban penyalahgunaan narkoba dan/atau psikotropika;dan memiliki kelainan lainnya.

3) Peserta didik yang memiliki potensi kecerdasan sebagimana dimaksud pada ayat (1) adalah peserta didik yang secara signifikan memiliki: IQ di atas 130 dengan skala Wechsler Intelligence Scale For Children (WISC) atau asesmen formal lainnya yang sederajat, kreativitas tinggi, kemampuan komitmen pada pekerjaan tinggi dan kemampuan umum dan akademik khusus di atas ratarata dalam bidang kepemimpinan.

4) Peserta didik yang memiliki potensi bakat istimewa sebagimana dimaksud pada ayat (1) adalah peserta didik yang secara signifikan memiliki potensi sangat menonjol atau di atas rata-rata anak seusianya dalam bidang seni dan/atau olahraga.

5) Untuk menetapkan peserta didik berkebutuhan khusus sebagaimana dimaksud pada ayat (3) dan ayat (4) dilakukan penilaian oleh tenaga ahli relevan yang ditentukan/direkomendasikan oleh Lembaga Pendukung Pendidikan Inklusif atau Pusat Sumber (Resource Center) dan/atau Asosiasi Penyelenggara Pendidikan Cerdas Istimewa/Bakat Istimewa.

Tujuan dari pendidikan inklusif adalah usaha sadar atau terencana untuk mewujudkan hak semua anak untuk menerima dan mendapatkan pendidikan yang layak yang tidak mendiskriminasi dengan kecacatan, etnis, agama, bahasa, jenis kelamin, kemampuan dan lain-lain.

Penyelenggaraan program pendidikan inklusif terbagi menjadi dua cara penyelengaraannya, yaitu ditunjuk secara resmi oleh Dinas Pendidikan dengan diberikannya Surat Keputusan (SK) atau pihak sekolah secara resmi mengajukan kepada Dinas Pendidikan untuk menyelenggrakan pendidikan inklusif di sekolah tersebut dengan syarat administrasi yang sudah sesuai.

Kriteria sekolah penyelenggara pendidikan inklusif juga dijabarkan dalam Prosedur Operasi Standar Pendidikan Inklusif, Direktorat Pembinaan Sekolah Luar Biasa (2007) sebagai berikut: kesiapan sekolah untuk menyelenggarakan program pendidikan inklusif (kepala sekolah, komite sekolah, guru, peserta didik, dan orang tua). Terdapat anak berkebutuhan khusus di lingkungan sekolah. Tersedia Guru Pendamping Khusus (GPK) dari PLB (guru tetap sekolah atau guru yang diperbantukan dari lembaga lain). Komitmen terhadap penuntasan wajib belajar. Memiliki jaringan kerjasama dengan lembaga lain yang relevan. Tersedia sarana penunjang yang mudah diakses oleh semua anak. Pihak sekolah telah memperoleh sosialisasi tentang pendidikan inklusif. Sekolah tersebut telah terakreditasi. Memenuhi prosedur administrasi yang ditentukan.

Sekolah Dasar (SD) Negeri Gunung Lipung 4 merupakan salah satu sekolah yang ditunjuk sebagai pelaksana pendidikan inklusif sejak di keluarkannya kebijakan pendidikan inklusif dalam Peraturan Walikota Tasikmalaya Nomor 46 Tahun 2014 Tentang Penyelenggaraan Pendidikan Inklusif di Kota Tasikmalaya. 
Sekolah Dasar Negeri Gunung Lipung 4 Kota Tasikmalaya memiliki 15 siswa inklusif yang terbagi ke dalam beberapa rombongan belajar.

Meskipun Kota Tasikmalaya sudah sudah mendeklarasikan sebagai Kota Pendidikan Inklusif pada tahun 2013 lalu (Sumber: Bandung Bisnis.com ) tapi dalam pengimplementasinya masih terdapat kendala yang dihadapi, seperti kurangnya sosialisasi ke masyarakat dikarenakan masyarakat belum sepenuhnya mengetahui tentang adanya pendidikan inklusi di daerahnya dan lebih mengenal sekolah (SLB) sebagai sekolah khusus untuk anak berkebutuhan khusus. Kemudian kurangnya sumberdaya manusia dalam mengoptimalkan program pendidikan inklusif juga kurangnya jumlah tenaga pendamping khusus yang mendampingi anak berkebutuhan khusus tersebut dan untuk saat ini guru pendamping masih merangkap menjadi guru kelas juga jadi beban kerja guru menjadi lebih banyak

Berdasarkan Peraturan Pemerintah Nomor 72 Tahun 1991 tentang Pendidikan Luar Biasa Bab 5 pasal 7 ayat 1 tentang syarat dan tata cara pendirian pendidikan inkusif tenaga kependidikan terdiri atas sekurang-kurangnya seorang guru kelas, dan seorang tenaga ahli. Sementara realitasnya SD Gunung Lipung 4 hanya memiliki satu tenaga ahli atau GPK yang merangkap sebagai guru kelas.

Berdasarkan problematika masalah yang dihadapi saat ini, penulis akan membahas tentang Implementasi Program Pendidikan Inklusif di SD Negeri 4 Gunung Lipung Kota Tasikmalaya. Indikator keberhasilan atau kegagalan suatu implementasi kebijakan publik dipengaruhi oleh empat faktor, antara lain: (1) Komunikasi, (2) Sumber Daya , (3) Disposisi, dan (4) Struktur Organisasi.

\section{METODE PENELITIAN}

Penelitian ini bertujuan untuk mengetahui bagaimana keberhasilan atau kegagalan implementasi penyelenggaraan dari kebijakan Pendidikan inklusif di Kota Tasikmalaya berdasarkan Peraturan Walikota Tasikmalaya Nomor 46 Tahun 2014 tentang Penyelenggaraan Pendidikan Inklusif di Kota Tasikmalaya dengan mengambil sample salah satu sekolah inklusif sebagai objek penelitian yaitu Sekolah Dasar (SD) Negeri Gunung Lipung 4 Kota Tasikmalaya. Tempat penelitian di SD Negeri Gunung Lipung 4 Kota Tasikmalaya yang beralamat di Jl. Ampera No. 181 Panglayungan, Kecamatan Cipedes, Kota Tasikmalaya. Adapun narasumber yang relevan dalam penelitian ini adalah salah satu Guru Pendamping Khusus (GPK) yang sekaligus menjadi koordinator khusus untuk program pendidikan inklusif di SD Negeri 4 Gunung Lipung.

Adapun fokus dari Penelitian ini adalah bagaimana hubungan antara pembuat kebijakan dan pelaksana kebijakan. Sumber daya yang dimiliki oleh SD Negeri Gunung Lipung 4 yang meliputi staf, sarana dan prasarana dan dana pendidikan. Disposisi SD Negeri 4 Gunung Lipung terhadap penerimaan murid inklusif dan struktur birokrasi.

Penelitian ini adalah deskriptif analitis, menurut (Sugiyono, 2015) metode deskriptif analitis merupakan metode yang bertujuan mendeskripsikan atau memberi gambaran terhadap suatu objek penelitian yang diteliti melalui sampel atau data yang telah terkumpul dan membuat kesimpulan yang berlaku umum.

Untuk kemudahan dalam penelitian, maka dibuat design penelitian seperti berikut: 


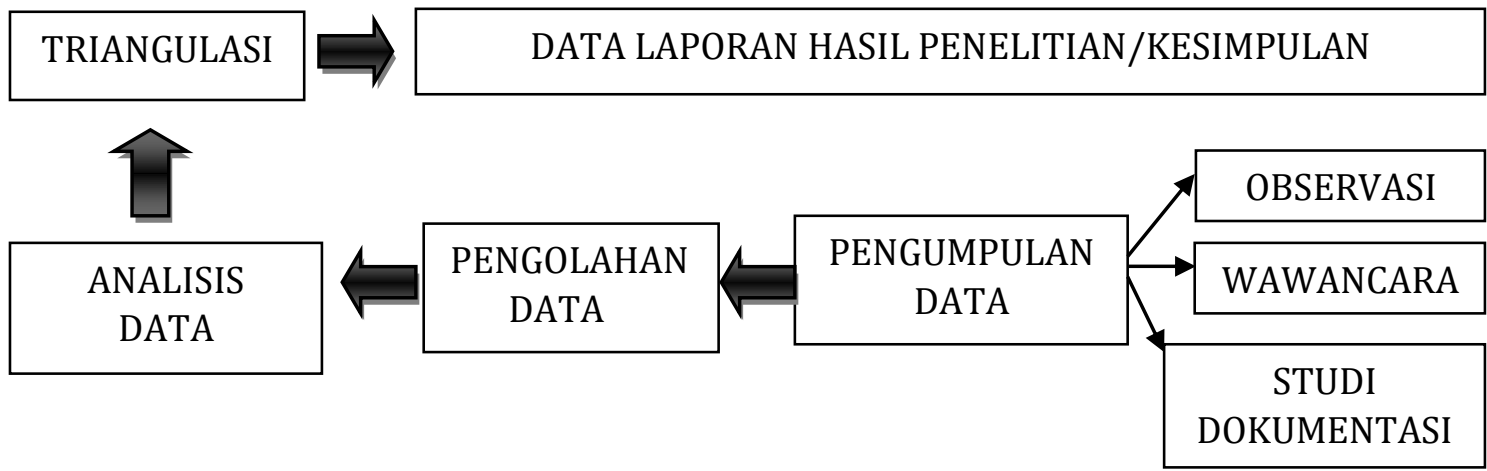

Gambar 1.

Desain Penelitian

Penelitian ini menggunakan teknis pengumpulan data sebagai berikut; Observasi, peneliti akan melakukan teknik observasi terus terang dan tersamar sebagai pendukung teknik wawancara,karena observasi yang dilakukan peneliti telah melalui perijinan terlebih dahulu serta terencana sehingga sumber data mengetahui pengamatan yang dilakukan oleh peneliti namun peneliti juga akan memastikan atau mengecek apakah hasil wawancara itu benar adanya. Wawancara, dalam penelitian ini peneliti akan melakukan teknik wawancara semi berstruktur sebagai salah satu teknik pengumpulan data. Ini didasarkan pada instrumen dan metode penelitian yang dipakai oleh peneliti dimana data sangat tergantung pada kondisi dan keadaan tempat atau objek yang akan di teliti.

Selanjutnya, dalam penelitian ini studi dokumentasi akan mendukung hasil dari wawancara dan observasi. Ketiga teknik pengumpulan data ini akan saling melengkapi dan mendukung, oleh karena itu peneliti memakai teknik wawancara, observasi dan studi dokumen dalam pengumpulan data.

Analisis data dalam penelitian ini dilakukan melalui tiga kegiatan yang terjadi secara bersamaan yaitu reduksi data, penyajian data, dan penarikan kesimpulan atau verifikasi (Sugiyono, 2015). Adapun untuk teknik validasi data peneliti menggunakan teknik validasi data Trigulasi, merupakan teknik pengumpulan data yang menggabungkan dari berbagai teknik pengumpulan data dan sumber data yang telah ada. Triangulasi dilakukan dengan cara mengecek pada sumber yang sama dengan teknik yang berbeda (Moleong, 2010).

Teknik triangulasi dalam penelitian ini dapat digambarkan sebagai berikut:

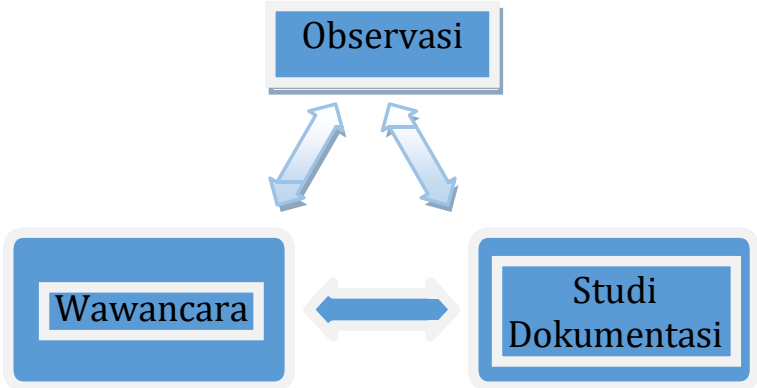

Gambar 2.

Letak Tringulasi 


\section{HASIL PENELITIAN DAN PEMBAHASAN}

Dalam penelitian ini, peneliti menggunakan teori implementasi kebijakan George C Edward III (1980), ada empat faktor atau variabel yang sangat penting dalam mengetahui keberhsailan atau kegagalan implementasi suatu kebijakan publik. Faktor tersebut antara lain:

1. Komunikasi

Menurut Edward III dalam Widodo (2010), komunikasi diartikan sebagai proses penyampaian informasi komunikator kepada komunikan. Informasi mengenai kebijakan publik perlu disampaikan kepada pelaku kebijakan agar para pelaku kebijakan dapat mengetahui apa yang harus mereka persiapkan dan lakukan untuk menjalankan kebijakan tersebut sehingga tujuan dan sasaran kebijakan dapat dicapai sesuai dengan yang diharapkan. Komunikasi kebijakan memiliki beberapa dimensi, antara lain dimensi transmisi (trasmission), kejelasan (clarity) dan konsistensi (consistency).

2. Sumber Daya (Resources)

Edward III dalam Widodo (2010) mengemukakan bahwa factor sumberdaya mempunyai peranan penting dalam implementasi kebijakan. Menurut Edward III dalam Widodo (2010) bahwa sumberdaya tersebut meliputi sumber daya manusia, sumber daya anggaran, dan sumber daya peralatan dan sumber daya kewenangan.

3. Disposisi (Disposition)

Pengertian disposisi menurut Edward III dalam Widodo (2010) dikatakan sebagai kemauan, keinginan dan kecenderungan para pelaku kebijakan untuk melaksanakan kebijakan tadi secara sungguh-sungguh sehingga apa yang menjadi tujuan kebijakan dapat diwujudkan.

4. Struktur Birokrasi

Edward III dalam Widodo (2010) menyatakan bahwa implementasi kebijakan bisa jadi masih belum efektif karena ketidakefisienan struktur birokrasi. Struktur birokasi ini menurut Edward III dalam Widodo (2010) mencakup aspek-aspek seperti struktur birokrasi, pembagian kewenangan, hubungan antara unit-unit organisasi dan sebagainya. Menurut Edwards III dalam Winarno (2005) terdapat dua karakteristik utama dari birokrasi yakni: Standard Operational Procedure (SOP) dan fragmentasi. SOP adalah suatu kegiatan rutin yang memungkinkan para pegawai (atau pelaksana kebijakan/administrator/birokrat) untuk melaksanakan kegiatan-kegiatannya pada tiap harinya sesuai dengan standar yang ditetapkan (standar minimum yang dibutuhkan warga). Sedangkan pelaksanaan fragmentasi adalah upaya penyebaran tanggung jawab kegiatan-kegiatan atau aktivitasaktivitas pegawai diantara beberapa unit kerja (Wardhani, 2015).

Pembahasan dari penelitian ini menggunakan teori George C Edward III (1980). terdapat 4 variabel untuk mengetahui keberhasilan suatu penerapan kebijakan antara lain :

1. Komunikasi

Terdapat beberapa variabel yang harus diperhatikan dalam komunikasi antara lain:

a. Transmisi

Penyampaian informasi atau transmisi yang dilakukan Dinas Pendidikan

Kota Tasikmalaya kepada SD Negeri 4 Gunung Lipung adalah melalui penunjukan sekolah Surat Keputusan (SK) dan dilandasi dengan Peraturan 
Walikota nomor 46 Tentang Penyelenggaraan Pendidikan Inklusif tahun 2014 dan kemudian dilanjutkan dengan workshop atau pelatihan selama kurang lebih 1 minggu secara berkala. Dalam hal penyampaian informasi tentang Program Pendidikan Inklusif kepada sasaran program tersebut, SD Negeri 4 Gunung Lipung melakukan sosialisasi secara berkala kepada wali murid ataupun masyarakat pada saat rapat wali murid tahun pelajaran baru atau rapat orangtua murid secara berkala dan juga pada Penerimaan Peserta Didik Baru mengenai program pendidikan inklusif yang di jalankan oleh SD Negeri 4 Gunung Lipung.

b. Kejelasan

Penyampaian informasi yang dilakukan Dinas Pendidikan Kota Tasikmalaya kepada SD Negeri 4 Gunung Lipung masih dirasa belum maksimal, jelas dan tidak terperinci karena setelah penunjukan sekolah untuk untuk melaksanakan program pendidikan inklusif kemudian dilanjut dengan pemberian SK dan setelah itu pihak Dinas Pendidikan tidak memberikan arahan apapun terkait teknis pelaksanaan program pendidikan inklusif. Tidak ada pelaporan rutin atau monitoring dan evaluasi tentang progress atau perkembangan program pendidikan inklusif di sekolah tersebut. Sekolah hanya memberikan laporan data penambahan dan pengurangan anak berkebutuhan khusus per tahun atau per tahun ajaran.

c. Konsistensi

Penerapan program pendidikan inklusif konsisten dilakukan dan tidak berubah semenjak ditunjuknya SD Negeri 4 Gunung Lipung sebagai sekolah inklusif. Program pendidikan lainnya juga konsisten dilakukan seperti program pendidikan karakter contohnya Pramuka yang wajib diikuti semua siswa tanpa terkecuali anak berkebutuhan khusus (ABK).

2. Sumber daya (Resources)

SD Negeri 4 Gunung Lipung memiliki 1 guru pendamping khusus (GPK) yang khusus menangani siswa berkebutuhan khusus tetapi juga merangkap sebagai guru kelas. SD Negeri 4 Gunung Lipung mempunyai 15 siswa inklusif dengan karakteristik 14 siswa dengan mental rendah atau slow learner dan 1 penyandang autisme atau gangguan sosialisasi.

Melihat dari banyaknya jumlah anak berkebutuhan khusus atau siswa inklusif dan dengan guru pendamping yang tidak seimbang, sekolah dan guru merasa tidak mencukupi dengan hal tersebut dan kurang maksimal dalam melakukan proses pendampingan belajar karena guru pendamping juga merangkap sebagai guru kelas. Setidaknya minimal 6 GPK untuk mendampingi 15 Siswa inklusif.

Selanjutnya dalam hal sarana dan prasarana atau fasilitas penunjang kegiatan pendidikan inklusif SD Negeri 4 Gunung Lipung memiliki fasilitas memadai dan memenuhi standar seperti adanya alat peraga pembelajaran, kursi roda, alat bantu diri (ABD) dan sarana penunjang lainnya. Tetapi perlu adanya penambahan pelengkapan fasilitas yang lebih variatif guna untuk menunjang proses belajar mengajar.

Dalam urusan mengenai dana dan hal-hal yang mendorong kemajuan pendidikan inklusif, pendanaan untuk program pendidikan inklusif masuk dalam 
anggaran sekolah yang berupa dana BOS, tetapi belum ada pendanaan khusus yang diberikan untuk Pendidikan Inklusif atau sejenisnya.

\section{Disposisi}

Disposisi terhadap siswa berkebutuhan khusus (inklusif) patut diapresiasi, tidak ada lagi bullying atau membedakan antara siswa berkebutuhan khusus dengan siswa (reguler). Semua siswa regular SD Negeri 4 Gunung Lipung juga menerima dengan baik dengan adanya siswa inklusif di lingkungan mereka, tetapi pada tahun-tahun awal sempat mengalami penolakan khususnya diantara orangtua murid dikarenakan anak berkebutuhan khusus perlu pendampingan khusus sehingga mungkin orang yang kurang paham terhadap hal seperti ini akan beranggapan lain maka diperlukan sosialisasi yang baik dan tepat terhadap penanganan hal tersebut.

\section{Struktur Organisasi}

Tidak ada perubahan dalam struktur organisasi di SD Negeri 4 Gunung Lipung terkait adanya program pendidikan inklusif ini, hanya penambahan dalam hal penanggung jawab terhadap siswa inklusif atau koordinator program pendidikan inklusif.

SD Negeri 4 Gunung Lipung cukup mendapatkan perhatian dari Pemerintah khususnya Dinas Pendidikan Kota Tasikmalaya dengan rutin diadakannya Diklat atau Training dari Pokja Dinas Pendidikan untuk semua guru pendamping di Kota Tasikmalaya. Juga pelatihan-pelatihan dari eksternal contohnya dari lembaga Rehabilitasi Berbasis Masyarakat (RBM). RBM menurut Slamet (1998) adalah aktivitas rehabilitasi bagi penyandang disabilitas dengan menggunakan sumber daya manusia. Dengan kata lain, bahwa aktivitas rehabilitasi didasarkan pada prinsip-prinsip pengembangan masyarakat. RBM menggunakan peran masyarakat dan keluarga dengan cara mengikutsertakan, menggerakan, atau memobilisasikan potensi sumber daya masyarakat mulai dari proses perencanaan, pelaksanaan, dan tindak lanjut kegiatan.

Tujuan utama rehabilitasi dalam penelitian ini adalah membantu penyandang disabilitas mencapai kemandirian optimal secara fisik, mental, sosial, vokasional, dan ekonomi sesuai dengan kemampuannya. Fokus rehabilitasi dalam penelitian ini adalah individu secara holistik dalam konteks ekologinya, bukan hanya pada keterbatasan-keterbatasan fungsional akibat disabilitasnya. Perspektif holistik dan ekologis mencakup aspek-aspek fisik, mental, dan spiritual individu yang bersangkutan maupun hubungannya dengan keluarganya, pekerjaannya dan keseluruhan lingkungannya sebagai suatu kesatuan yang utuh (Ranti Novianti, 2017).

RBM juga rutin mengadakan workshop dan sosialisasi kepada masyarakat umum maupun pihak sekolah dengan bekerja sama dengan pemerintah melalui dinas sosial dan beberapa rumah sakit daerah atau klinik terkait pemahaman tentang disabilitas juga mengadakan kegiatan layanan terapi anak disabilitas yang meliputi beberapa layanan terapi seperti fisioterapis, terapi wicara, okupasi terapi serta pemberian alat bantu untuk penyandang disabilitas (sumber: dinsos.tasikmalayakota.go.id). 


\section{KESIMPULAN}

Berdasarkan data dan hasil analisis serat pembahasan tentang bagaiamana Implementasi Pendidikan Inklusif di SD Negeri 4 Gunung Lipung, maka didapat beberapa kesimpulan sebagai berikut: (1) SD Negeri 4 Gunung Lipung sudah menjalankan program pendidikan inklusif dengan maksimal dalam hal penerapan dan implementasi kebijakan tersebut. (2) Proses Komunikasi atau penyampaian kebijakan oleh Dinas Pendidikan Kota Tasikmalaya untuk menyampaikan atau mentransmisikan program pendidikan inklusif yaitu dengan menunjuk serta memberi kuasa berupa Surat Keputusan (SK) penunjukan, pembekalan, dan training kepada sekolah SD Negeri 4 Gunung Lipung, kemudian menyampaikan program tersebut kepada sasaran kebijakan SD Negeri 4 Gunung Lipung melalui sosialisasi dalam pertemuan orangtua murid dan di PPBD. Komunikasi antar pembuat kebijakan dengan pelaksana kebijakan masih belum sepenuhnya terjalin masih ada beberapa faktor yang belum jelas dan belum sepenuhnya maksimal. (3) Untuk sumber daya sarana berupa fasilitas-fasilitas pendukung kegiatan program pendidikan inklusif masih dirasa belum sepenuhnya terpenuhi dan masih perlu penambahan guna mendukung dalam program pendidikan inklusif. Dan perlu perhatian lebih dari Dinas Pendidikan terkait pemisahan penugasan guru pendamping khusus dan guru kelas karena dirasa kurang maksimal jika dikerjakan rangkap jabatan kerja atau tanggungjawab kerja. (4) Guru-guru dan siswa-siswa SD Negeri 4 Gunung Lipung sudah memiliki Disposisi atau watak dan karakter yang maksimal dalam hal menerima murid atau siswa inklusif. (5) Untuk struktur birokrasi di SD Negeri 4 Gunung Lipung tidak mengalami perubahan terlalu banyak tetapi ada penambahan koordinator untuk siswa inklusif.

Berdasarkan kesimpulan tersebut tentang kebijakan implementasi pendidikan inklusif di SD Negeri 4 Gunung Lipung, maka terbentuk beberapa saran yang bisa dijadikan bahan pertimbangan atau evaluasi seperti: penambahan fasilitas sarana prasarana dan pelatihan-pelatihan guru atau tenaga pendamping perlu diadakan secara rutin mengenai program-program mengenai pendidikan inklusif supaya mengenal lebih banyak informasi tentang pendidikan inklusif. Program evaluasi serta monitoring perlu dilakukan minimal 1 tahun 2 kali untuk mengetahui progres perkembangan manfaat dari pendidikan inklusif bagi anak berkebutuhan khusus (ABK). Perlu adanya penambahan Guru Pendamping Khusus (GPK) supaya pelayanan pendidikan inklusif lebih maksimal dan perlu dikaji terkait penugasan guru pendamping khusus karena guru pendamping khusus (GPK) masih rangkap jabatan menjadi guru kelas.

\section{DAFTAR PUSTAKA}

Aan Komariah dan Djam'an Satori. 2012. Metodologi Penelitian Kualitatif. Bandung: Alfabeta.

AG Subarsono. 2009. Analisis Kebijakan Publik Konsep Teori dan Aplikasi. Yogyakarta. 
Eko Puji Lestari, S. P. 2018. Kebijakan Penyelenggaraan Pendidikan Inklusif Di Indonesia. 45.

Eneng Dewi Wulansari. 2019. Pengaruh Implementasi Kebijakan Gerakan Indonesia Sadar Administrasi Kependudukan (GISA) terhadap Peningkatan Kualitas Pelayanan Administrasi Kependudukan di Dinas Kependudukan dan Pencatatan Sipil Kota Bandung. 3 (September), 1-47.

Ertien Rining Nawangsari. 2017. Implementasi Pendidikan Inklusif di SMA Negeri 1 Gedangan Sidoarjo. 9 (2), 174-183.

Firdaus, E. 2010. Pendidikan Inklusif Dan Implementasinya di Indonesia. Disampaikan dalam Seminar Nasional Pendidikan di Universitas Jenderal Soedirman (UNSOED) Purwokerto, 24 Januari 2010.

https://bandung.bisnis.com/read/20131217/549/1029811/tasikmalayadeklarasikan-kota-pendidikan-insklusif di akses tanggal 2 Mei 2020.

https://dinsos.tasikmalayakota.go.id/rehabilitasi-sosial-berbasis-masyarakatrbm-karang-anyar-kec-kawalu-kota-tasikmalaya-melakukan-kegiatanpelayanan-terapi-anak-disabilitas/ diakses tanggal 27 Mei 2020.

https://muhammadpranaadithya.gurusiana.id/article/2020/2/penyelenggaraanpendidikan-inklusif-2010708 diakses tanggal 27 Mei 2020.

Khoeriyah, N. 2019. Pandangan Ki Hajar Dewantara tentang Pendidikan Anak Usia Dini dan Relevansinya dengan Pendidikan Islam. Duke Law Journal, 1 (1), 113. https://doi.org/10.1017/CB09781107415324.004.

Moleong, L. J. 2010. Metodelogi Penelitian Kualitatif. Bandung: PT. Remaja Rosdakarya.

Mustarjudin. 2017. Efektivitas Juru Bahasa Isyarat khutbah di Masjid UIN Sunan Kalijaga. Inklusi, 4 (2), 271-296.

Peraturan Menteri Pendidikan Nasional Nomor 70 Tahun 2009 Tentang Pendidikan Inklusif Bagi Peserta Didik Yang Memiliki Kelainan dan Memiliki Potensi Kecerdasaan dan/atau Bakat Istimewa.

Peraturan Pemerintah Nomor 72 Tahun 1991 tentang Pendidikan Luar Biasa.

Peraturan Walikota Tasikmalaya Nomor 46 Tahun 2014 Tentang Penyelenggaraan Pendidikan Inklusif di Kota Tasikmalaya.

Ranti Novianti, H. A. A. 2017. Rehabilitasi Berbasis Masyarakat sebagai Upaya Memenuhi Kebutuhan Anak dengan Disabilitas. III (01), 109-115. 
Sita, A. A. A., Wijayanti, D., Noak, P. A., \& Purnamaningsih, P. E. 2003. Implementasi Penyelenggaraan Pendidikan Inklusif bagi Anak Berkebutuhan Khusus (ABK) dalam Lingkup Sekolah Inklusi (Studi Kasus: SD No. 11 Jimbaran). Ilmu Sosial Dan Ilmu Politik, 2 (11).

Sudarto, Z. 2017. Implementasi Kebijakan Penyelenggaraan Pendidikan Inklusif. Jurnal Pendidikan (Teori dan Praktik), 1 (1), 97. https://doi.org/10.26740/jp.v1n1.p97-106.

Sugiyono. 2015. Memahami Penelitian Kualitatif. Bandung: Alfabeta.

Undang-Undang No. 20 Tahun 2003 tentang Sistem Pendidikan Nasional.

Wardhani, P. A. 2015. Efikasi Diri dan Pemahaman Konsep IPA dengan Hasil Belajar Ilmu Pengetahuan Alam Siswa Sekolah Dasar Negeri Kota Bengkulu. Jurnal Pendidikan Dasar, 6 (1), 10-36.

Winarno, Budi. 2002. Teori dan Proses Kebijakan Publik. Yogyakarta: Media Pressindo. 